\title{
Comprehensive Evaluation of Urban Low-carbon Economy Based on Grey
}

\section{Correlation}

\author{
Xiao-yi Xiong ${ }^{1}$ \\ International Education College \\ Hebei Finance University \\ Baoding, China
}

\author{
Yan-zi Li ${ }^{2}$ \\ International Education College \\ Hebei Finance University \\ Baoding, China
}

\begin{abstract}
It founds a hierarchical index system for evaluating urban low-carbon economic development from four aspects, such as social system, economic system, technology system and environmental system. Paper proposes a comprehensive evaluation model based on gray correlation, screening each two strongly correlated indicators, eliminating redundancy and reducing the complexity of the evaluation process. The model applies objective weighting method to determine the comprehensive weight of each index, improving the accuracy of the evaluation results. Based on the announced data of some province, the example indicates the rationality and effectiveness of the method.
\end{abstract}

Keyword: Urban low-carbon; Grey correlation; Entropy weight; Comprehensive evaluation

\section{INTRODUCTION}

At present, the low carbon economy taking low energy consumption, low pollution, low emission for purport has become a new economic development model. The essence of low carbon economy is energy efficient utilization, clean energy development, and the pursuit of green GDP. In the context of advocating sustainable development, a society must accelerate the construction of low carbon economy. Therefore, how to evaluate the low carbon economy development is particularly important ${ }^{[1]}$.

\section{Establishment of urban low-carbon economy evaluation index system}

Combining with the actual situation of urban low-carbon economy, on the basis of the hierarchical classification thought, a hierarchical hierarchical evaluation index system of urban low-carbon economy is established, which shown in Table $1^{[2]}$.

Table 1. Urban low-carbon economy evaluation index system

\begin{tabular}{|c|c|}
\hline $\begin{array}{l}\text { Principle } \\
\text { layer }\end{array}$ & Index layer \\
\hline \multirow{11}{*}{$\begin{array}{c}\text { Social } \\
\text { systems }\end{array}$} & Urbanization rate $X_{11}$ \\
\hline & Engel coefficient $X_{12}$ \\
\hline & Per capita housing area \\
\hline & $\mathrm{X}_{13}$ \\
\hline & Bus number per ten \\
\hline & thousand people $X_{14}$ \\
\hline & Annual per capita carbon \\
\hline & emissions $\quad X_{15}$ \\
\hline & $\mathrm{SO}_{2}$ emissions of unit GDP \\
\hline & $\mathrm{X}_{16}$ \\
\hline & Motor vehicle amount $X_{17}$ \\
\hline \multirow{8}{*}{$\begin{array}{c}\text { Economic } \\
\text { system }\end{array}$} & $\begin{array}{l}\text { Per capita net income of } \\
\text { rural residents } \mathrm{X}_{21}\end{array}$ \\
\hline & Urban per capita disposable \\
\hline & income $\mathrm{X}_{22}$ \\
\hline & Per capita GDP growth $X_{23}$ \\
\hline & The tertiary industry output \\
\hline & value of a share of GDP $X_{24}$ \\
\hline & Low carbon industry output \\
\hline & value $X_{25}$ \\
\hline \multirow{3}{*}{$\begin{array}{l}\text { Technolo } \\
\text { gy system }\end{array}$} & Energy consumption \\
\hline & elasticity coefficient $X_{31}$ \\
\hline & Low energy consumption \\
\hline
\end{tabular}


building $\mathrm{X}_{32}$

Comprehensive utilization

of industrial "three wastes"

product output $\mathrm{X}_{33}$

Energy consumption per unit

GDP $_{34}$

The proportion of new

energy $\mathrm{X}_{35}$

Hazard-free treatment rate of

household garbage $\mathrm{X}_{36}$

Nature reserve area $X_{41}$

Urban greenbelt area per

Environm capita $\mathrm{X}_{42}$

ental Forest coverage rate $\mathrm{X}_{43}$

system Environmental protection

investment as a share of

GDP $_{44}$

\section{Grey correlation theory}

Grey correlation analysis is a kind of new factors analysis, mainly analyzes the correlation degree between various factors in the system according to comparing the geometric relationships of the data sequence. Grey correlation clustering algorithm is shown as follows ${ }^{[3]}$ :

Set $n$ evaluation objects, each evaluation has $m$ indexes. Then get the following sequence:

$$
\begin{gathered}
X_{1}=\left(x_{1}(1), x_{1}(2), \cdots, x_{1}(n)\right) \\
X_{2}=\left(x_{2}(1), x_{2}(2), \cdots, x_{2}(n)\right) \\
\vdots \\
X_{m}=\left(x_{m}(1), x_{m}(2), \cdots, x_{m}(n)\right)
\end{gathered}
$$

(1) Set correlation sequence as

$$
X_{i}\left(x_{i}(1), x_{i}(2), \cdots, x_{i}(n)\right) \text {. }
$$

Set the Broken line as

$$
X_{i}^{0}=X_{i}-x_{i}(1)
$$

Set $a_{i}=\int_{1}^{n}\left(X_{i}-x_{i}(1)\right) d t$, which expresses the enclosed area of the broken line $X_{i}-x_{i}(1)$.

Set another Broken line as

$$
X_{j}^{0}=X_{j}-x_{j}(1)
$$

Set $a_{j}=\int_{1}^{t}\left(X_{j}-x_{j}(1)\right) d t$, which expresses the enclosed area of the broken line $X_{j}-x_{j}(1)$.

Set $a_{i}-a_{j}=\int_{1}^{n}\left(X_{i}^{0}-X_{j}^{0}\right) d t$, which expresses the size relationship between $X_{i}^{0}$ and $X_{j}^{0}$.

(2) Respectively calculate $\left|a_{i}\right|,\left|a_{j}\right|$ and $\left|a_{i}-a_{j}\right|$.

And the value of $r_{i j}=\frac{1+\left|a_{i}\right|+\left|a_{j}\right|}{1+\left|a_{i}\right|+\left|a_{j}\right|+\left|a_{i}-a_{j}\right|}$ is defined as the grey absolute correlation degree between $X_{i}$ and $X_{j}$.

\section{Using entropy weight method to determine the weight of indexes}

Entropy method is a kind of method to determine the weight of indexes according to the amount of information provided by observation index value. The information entropy of the index is smaller, indicating that indicators can provide more information content, the greater role in the evaluation of. The basic process is as follows ${ }^{[4]}$ :

(1) Standardization of the indicators, eliminating the impact of the different dimensions and indicators of the positive reverse.

(2) Calculate the value of $p_{i j}$, which represents the $j$-th objective proportion of the $i$-th index.

$$
p_{i j}=y_{i j} / \sum_{i=1}^{m} y_{i j}
$$

(3) Calculate the entropy value $h_{j}$ of the $j$-th index.

$$
h_{j}=-\frac{1}{\ln m} \sum_{i=1}^{m} p_{i j} \ln p_{i j}
$$


(4) Calculate the difference coefficient $g_{j}$ of the $j$-th index. For the $j$-th index, if the value of $h_{j}$ is smaller, the difference degree of the indicator value is larger, and its difference coefficient is smaller. The difference coefficient is defined as follows:

$$
g_{j}=1-h_{j}
$$

(5) Calculate the weight $w_{j}$ of the $j$-th index.

$$
w_{j}=g_{i j} / \sum_{j=1}^{n} g_{j}
$$

\section{Case analysis}

This paper applies the urban low carbon economy comprehensive evaluation index system shown in Table 1and the relevant index calculation method. At the same time, the index data of eight cities in a certain province in 2013 index data are calculated each index value.

\subsection{The secondary index analysis based on grey correlation}

On the basis of the calculated index data, regard the first level indicators as the grouping criteria, calculate among the absolute correlation of the secondary indicators. When the absolute correlation degree of the secondary index reaches to 0.5 , these two index are regarded as a joint.

For the social system, the absolute correlation degree between the urbanization rate, the Engel coefficient and the annual per capita carbon emissions are respectively 0.64 , 0.68 and 0.66 , which are all bigger than 0.5. The final social system evaluation indexes are summarized as $X_{11}, X_{13}, X_{14}, X_{16}, X_{17}$. For the economic system, the absolute correlation degree between the per capita disposable income of urban residents and the per capita GDP of the growth rate is 0.67 which is bigger than 0.5 . In addition, that value between third industrial output value and low carbon industry output value is 0.58 , also bigger than 0.5 . The final economic system evaluation indexes are summarized as $X_{21}, X_{22}, X_{24}$. For the technology system, the absolute correlation degree between the energy consumption elasticity coefficient and the unit GDP energy consumption is 0.65 , the proportion of low energy consumption buildings and new energy sources accounted for the ratio is 0.62 . The final technology system evaluation indexes are summarized as $X_{33}, X_{35}, X_{36}$. For the environmental system the absolute correlation degree between the area of the nature reserve and forest cover is 0.55 . The final environmental system evaluation indexes are summarized as $X_{42}, X_{43}, X_{44}$.

\subsection{Comprehensive evaluation of urban low-carbon economy}

The comprehensive evaluation values $Z_{i}$ of each city are calculated according to the index value and its weight. The formula of the comprehensive evaluation is as follows:

$$
Z_{i}=x_{i j} w_{j}
$$

Using the formula (5) to calculate the comprehensive evaluation value and ranking results of the eight cities, specifically shown in Table 2.

Table 2. The results of comprehensive evaluation

\begin{tabular}{ccc}
\hline Urban No. & $\begin{array}{c}\text { evaluation } \\
\text { value }\end{array}$ & Ranking \\
\hline 1 & 0.825 & 1 \\
2 & 0.664 & 3 \\
3 & 0.645 & 4 \\
4 & 0.396 & 8 \\
5 & 0.420 & 7 \\
6 & 0.682 & 2 \\
7 & 0.638 & 5 \\
8 & 0.487 & 6 \\
\hline
\end{tabular}

As can be seen in Table 2, No.1 belongs to the low carbon economy urban, No. 2, 3, 6, 7 belong to sub low carbon economy urban, No. 4, 5 and 8 belong to high carbon economy urban. For the latter ones, it should not 
only be focus on the development of social economy, but also save energy, increase investment in environmental protection, and get rid of the pattern of high carbon economy development.

\section{Conclusions}

In order to reflect the city's low carbon economic development status, this paper established the evaluation index system of low carbon economic. The grey correlation and entropy weight method are used to calculate the comprehensive evaluation value of each index. The proposed model can simplify the evaluation process and avoid the interference of subjective factors, and to fully exploit the information contained in the data. The case analysis results show that the evaluation model is effective and feasible..

\section{References}

[1] Huang Yuansheng, Yang Hongjie, "Integrated Evaluation Model of Urban Low-carbon Economy Based on Gray Relational," Value Engineering, pp. 267-269, 2013.

[2] Wang Wenjun, "Experience and Enlightenment of Foreign Countries and China's Development of Low-carbon Economy," Journal of Northwest A\&F University (Social Science Edition), pp. 73-77, 2009.

[3] Luo Dang, Liu Sifeng, "Study on the Method for Grey Incidence Decision-Making," Chinese Journal of Management Science, pp. 101-106, 2005.

[4] Zhang Sui, Zhang Mei, Chi Guotai, "The Science and Technology Evaluation Model Based on Entropy Weight and Empirical Research During the10th Five-Year of China," Chinese Journal of Management, pp. 34-42, 2010. 